\title{
Post-Transcriptional Gene Silencing in the Root System of the Actinorhizal Tree Allocasuarina verticillata
}

\author{
Hassen Gherbi, ${ }^{1}$ Mathish Nambiar-Veetil, ${ }^{1,2}$ Chonglu Zhong, ${ }^{1,3}$ Jessy Félix, ${ }^{1}$ Daphné Autran, ${ }^{1}$ \\ Raphaël Girardin, ${ }^{1}$ Virginie Vaissayre, ${ }^{1}$ Florence Auguy, ${ }^{1}$ Didier Bogusz, ${ }^{1}$ and Claudine Franche ${ }^{1}$ \\ ${ }^{1}$ Equipe Rhizogenèse, UMR DIA PC, IRD (Institut de Recherche pour le Développement), 911 avenue Agropolis, BP 64501, \\ 34394 Montpellier Cedex 5, France; ${ }^{2}$ Plant Biotechnology Division, Institute of Forest Genetics and Tree Breeding, Forest \\ Campus, R. S. Puram, Coimbatore 641002 India; ${ }^{3}$ Research Institute of Tropical Forestry, Chinese Academy of Forestry, \\ Longdong, Guangzhou 510520, China
}

Submitted 15 November 2007. Accepted 27 January 2008.

In recent years, RNA interference has been exploited as a tool for investigating gene function in plants. We tested the potential of double-stranded RNA interference technology for silencing a transgene in the actinorhizal tree Allocasuarina verticillata. The approach was undertaken using stably transformed shoots expressing the $\beta$-glucuronidase (GUS) gene under the control of the constitutive promoter $35 \mathrm{~S}$; the shoots were further transformed with the Agrobacterium rhizogenes A4RS containing hairpin RNA (hpRNA) directed toward the $G U S$ gene, and driven by the $35 S$ promoter. The silencing and control vectors contained the reporter gene of the green fluorescent protein (GFP), thus allowing a screening of GUS-silenced composite plantlets for autofluorescence. With this rapid procedure, histochemical data established that the reporter gene was strongly silenced in both fluorescent roots and actinorhizal nodules. Fluorometric data further established that the level of $G U S$ silencing was usually greater than $90 \%$ in the hairy roots containing the hairpin $G U S$ sequences. We found that the silencing process of the reporter gene did not spread to the aerial part of the composite $A$. verticillata plants. Real-time quantitative polymerase chain reaction showed that GUS mRNAs were substantially reduced in roots and, thereby, confirmed the knock-down of the $G U S$ transgene in the $\mathrm{GFP}^{+}$hairy roots. The approach described here will provide a versatile tool for the rapid assessment of symbiotically related host genes in actinorhizal plants of the Casuarinaceae family.

Additional keywords: actinorhizal symbiosis, Frankia.

During a deficiency of reduced nitrogen sources, actinorhizal plants such as Allocasuarina verticillata, a member of the Casuarinaceae family, are able to live symbiotically with actinomycetes of the genus Frankia. The symbiosis results in the formation of specialized root organs, actinorhizal nodules, inside which Frankia spp. reduce atmospheric nitrogen to ammonium for the benefit of the host plant (Benson and Silvester

Corresponding author: Claudine Franche; E-mail: franche@mpl.ird.fr

This article is in the public domain and not copyrightable. It may be freely reprinted with customary crediting of the source. The American Phytopathological Society, 2008.
1993; Pawlowski 2002). Compared with the Rhizobium spp.legume symbiosis, the actinorhizal symbiosis shows original properties (Pawlowski and Bisseling 1996; Vessey et al. 2005). With 24 genera from eight plant families, actinorhizal plants are characterized by a wide taxonomic diversity. One of the striking features of the gram-positive filamentous actinomycete genus Frankia is its ability to develop two developmental structures that are critical to its survival, vesicles and spores. The vesicle is the site for actinorhizal nitrogen fixation while spores are the reproductive structure of Frankia spp. In legumes, infection is induced by lipochitooligosaccharide signal molecules (LCO), so-called Nod factors, that are secreted by rhizobia. Proteins encoded by the bacterial $\operatorname{nod} A$, $\operatorname{nod} B$, and nodC genes are involved in the biosynthesis of the basic LCO structure that consist of a tri-, tetra-, or pentameric chitin backbone, with a fatty acid attached to the nitrogen of the nonreducing sugar (Dénarié et al. 1996). Preliminary analyses of sequences of the Frankia genome revealed some disperse putative nod-like genes in the actinomycete. However, these genes do not appear to be organized in clusters as in rhizobia and $\operatorname{nod} A$, at least, is not present, thus suggesting that the synthesis of LCO by Frankia spp. is unlikely (Normand et al. 2007). Finally, actinorhizal nodules arise from lateral root primordia and retain the structure of a modified lateral root, whereas legume nodules have a stem-like anatomy with peripheral vascular bundles (Pawloswki and Bisseling 1996). Therefore, further progress in the molecular knowledge of actinorhizal symbioses is important for the comparison of nodule ontogenesis with legumes; however, many of the tools developed for the functional analysis of model plants are not available for use on woody plant species such as Casuarinaceae trees (Obertello et al. 2007).

RNA silencing involves suppression of gene expression by sequence-specific interaction with RNA at the post-transcriptional level. This phenomenon first was discovered and termed post-transcriptional gene silencing (PTGS) in plants, quelling in fungi, and RNA interference (RNAi) in animals (Waterhouse and Helliwell 2003). RNA silencing is initiated by the formation of double-stranded RNAs (dsRNA) that are cut into smaller dsRNA species 21 to 25 nucleotides (nt) in length, termed small interfering RNAs (siRNAs), by an RNaseIII-like enzyme called DICER. siRNAs then incorporate into a multisubunit ribonuclease, referred to as RNA-induced silencing complex (RISC) (Hannon 2002), and act as guides to specifically degrade RNAs that share sequence similarity with the 
dsRNA, thus resulting in gene silencing. In addition to intracellular gene silencing, silencing also is transmitted from cell to cell. After initiation and amplification of the cytoplasmic RNA silencing pathway, the final step of the process involves spreading first to neighboring cells and then systematically throughout the plant. Cell-to-cell movement of the silencing signal occurs through plasmodesmata (Kobayashi and Zambryski 2007) and long-distance movement is through the phloem (Voinnet and Baulcombe 1997). In plants, RNA silencing plays important roles in diverse biological processes, including developmental regulation, antiviral defense, and chromatin remodeling (Baulcombe 2004).

Modulating gene expression in plants using either antisense or sense constructs usually produces effective gene silencing in no more than 10 to $20 \%$ of a transgenic population (Hamilton et al. 1998; Smith et al. 2000). A major increase in the frequency of PTGS is obtained when transformation is achieved with a hairpin RNA (hpRNA) construct composed of an inverted repeat of the gene of interest with an intron between the inverted repeat elements (Smith et al. 2000; Waterhouse et al. 1998). The potential of hpRNA for suppression of gene expression has been established for a number of plants, including tobacco, Arabidopsis thaliana, and the moss Physcomitrella patens (Baulcombe 2004). In recent years, RNA silencing has been exploited as a tool for validating the function of candidate genes from the model legumes Lotus japonicus and Medicago truncatula, predicted to be involved in the symbiotic interaction with the nitrogen-fixing bacteria Rhizobium spp. (Boisson-Dernier et al. 2001; Kumagai et al. 2006; Limpens et al. 2003). Downregulation of gene expression also has been demonstrated in a forest tree (poplar) using both transient assays and stably transformed plant material (Meyer et al. 2004). The discovery of dsRNA silencing has opened up new possibilities for genome-wide, high-throughput functional genomics in plants, and large-scale silencing projects using transformation with constructs that contain hpRNA have been initiated in A. thaliana, maize, and M. truncatula (Small 2007).

In this study, we examined the power of RNAi technology in the actinorhizal tree $A$. verticillata. $\beta$-Glucuronidase (GUS) silencing constructs were expressed in stably transformed lines expressing the GUS gene (Jefferson et al. 1987) under the control of the Cauliflower mosaic virus $35 S$ promoter (Benfey and Chua 1990). The 35S-driven RNAi constructs were introduced into A. verticillata by Agrobacterium rhizogenes-mediated transformation (Diouf et al. 1995) and cotransformation was followed by fluorescence linked to the green fluorescent protein (GFP) reporter gene (Niwa et al. 1999). A detailed histochemical analysis of the GUS-silencing pattern was undertaken in composite plants nodulated by the nitrogen-fixing actinomycete Frankia spp. Quantification of GUS activity by fluorometry, and mRNA levels by real-time quantitative polymerase chain reaction (qPCR) were used to study the extent of GUS gene knock-down in A. verticillata. Here, we show that silencing of the GUS gene is highly effective in actinorhizal roots and nodules, and discuss this important finding for further functional analysis of plant genes involved in the symbiotic process with Frankia spp.

\section{RESULTS AND DISCUSSION}

\section{Agrobacterium tumefaciens-mediated transformation of $A$. verticillata.}

The Agrobacterium tumefaciens C58C1(pGV2260; pBinGUSint) was used to genetically transform 200 epicotyl fragments of $A$. verticillata following the procedure previously described (Franche et al. 1997). After 4 months of selection on kanamycin, 36 callus lines resulting from different events of T-
DNA insertion were obtained. Seven $35 S-G U S$ callus lines were chosen for further analysis based on the following criteria: a good callus growth, the organogenic potential of the calli leading to the differentiation of numerous transgenic shoots, intense and constitutive blue staining after incubation of the shoots in 5-bromo-4-chloro-3-indolyl-D-glucuronide (X-gluc), and the presence of only one copy of the GUS gene (Southern blot analysis not shown).

\section{Generation of composite $35 S$ - $G U S$ plants of $A$. verticillata by Agrobacterium rhizogenes.}

To test the effectiveness of PTGS in A. verticillata trees, three different binary vectors called pHKN (Kumagai and Kouchi 2003) were used. pHKN29 is a control vector without RNAi sequence; it contains the reporter gene GFP (Niwa et al. 1999) under the control of the constitutive $35 S$ promoter, thereby allowing the nondestructive identification of cotransformed plant cells. pHKN30 and pKN31 are derivatives of pHKN29 that include a palindromic GUS sequence under the control of the $35 S$ promoter. The hpRNA construct in pHKN30 contains a sequence of $582 \mathrm{nt}$ at the $3^{\prime}$ end of the GUS coding region and $\mathrm{pHKN} 31$ contains a $325-\mathrm{nt}$ sequence at the middle part of the GUS coding region.

To obtain composite plants that consisted of transgenic hairy roots induced by Agrobacterium rhizogenes on a $35 S-G U S$ aerial system, shoots were excised from the selected $35 S-G U S$ callus lines and dipped in fresh colonies of A4RS(pHKN). Controls included $35 S-G U S$ shoots without inoculation with $A$. rhizogenes. One week after inoculation, a small callus was observed at the base of the inoculated shoots and, 1 week later, one to five rapidly growing roots had differentiated on $63 \%$ of the inoculated shoots (Fig. 1A). One or two roots spontaneously developed at the base of approximately $38 \%$ of the control shoots that had no contact with A4RS(pHKN). These roots showed a normal growth rate; they were $1.3 \pm 0.4 \mathrm{~cm}$ long 3 weeks after shoot excision, whereas roots observed after inoculation by $A$. rhizogenes were $3.8 \pm 0.9 \mathrm{~cm}$ long.

Bright green fluorescent sectors were observed in approximately half of the calli resulting from the inoculation of the shoot base by the A4RS(pHKN) strains (data not shown). In young roots that emerged 2 to 3 weeks after inoculation, the fluorescence was easily observed in $19 \pm 14 \%$ of the fast-growing roots (Fig. 1B). When roots developed secondary xylem, the fluorescence was more difficult to observe, except in young lateral roots, in cracked area of lignified roots, and in the apical region of the primary root. As previously reported, no fluorescence was observed in untransformed control roots of $A$. verticillata (Santi et al. 2003).

The efficiency of transformation of A. verticillata is comparable to other reported systems. In Agrobacterium rhizogenesmediated genetic transformation of $M$. truncatula, cotransformation varied between experiments; however, on average, $30 \%$ of the newly formed roots were cotransformed, and one to three cotransformed roots grew per inoculated seedling (Limpens et al. 2004). In Arabidopsis thaliana, efficiency rates of up to $20 \%$ were reached. In both $M$. truncatula and A. thaliana, chimaeric roots with fluorescent and nonfluorescent sectors were reported in approximately 50 and $10 \%$, respectively, of the hairy roots. No chimeric hairy roots consisting of transformed and untransformed cells were observed in the composite plants of $A$. verticillata.

Silencing of GUS activity in composite $A$. verticillata plants. As previously reported (Franche et al. 1997; Obertello et al. 2005), a strong GUS expression was observed in the control $A$. verticillata plants resulting from the genetic transformation by C58C1(pGV2260; pBinGUSint). GUS activity was completely 
or strongly reduced in the fluorescent roots resulting from the T-DNA transfer of the pHKN30 and pHKN31 vectors that contain 35S-GUS-hpRNAs compared with both control plants and pHKN29 composite plants (Fig. 1C through J). Approximately $70 \%$ of the $\mathrm{GFP}^{+}$hairy roots showed no blue staining in either primary or lateral roots (Fig. $1 \mathrm{E}$ and $\mathrm{F}$ ). In the remaining $\mathrm{GFP}^{+}$ composite plants, some GUS activity was still visible in specific locations that differed from plant to plant. The GUS patterns observed were either restricted to the apical region of the main root (Fig. 1G) or included both the apex (root cap and root meristem) and the vascular system in the elongation zone (Fig. 1H); sometimes the apex showed no blue staining whereas staining was visible in the vascular system (data not shown). Occasionally, some GUS expression was seen in the area of emergence of lateral roots or the vascular cylinder of the lateral roots (Fig. 1I and J). Similar patterns were observed in fluorescent roots silenced either with the hpRNA of pHKN30 or with that of pHKN31. In both cases, no GUS activity was seen to persist in the root hairs (data not shown). Experiments of post-transcriptional silencing of transgenes in Nicotiana benthamiana have shown that the gene silencing mechanism is not effective in meristematic plant tissues because the silencing signal cannot reach those regions (Voinnet et al. 1998). In L. japonicus, silencing appears to be more pronounced than in A. verticillata because Kumagai and Kouchi (2003) reported that they did not detect GUS activity in any part of the $\mathrm{GFP}^{+}$roots, including the root hairs and the root apical meristem.

When composite plants of $A$. verticillata were found to possess both $\mathrm{GFP}^{+}$and $\mathrm{GFP}^{-}$fluorescent roots, GUS activity was detected only in nonfluorescent roots, thus indicating that silencing observed in the $\mathrm{GFP}^{+}$roots did not spread to noncotransformed adjacent roots. Similar data have been reported in L. japonicus, Arabidopsis thaliana, and M. truncatula, where systemic transport of the silencing signal to non-cotransformed roots did not occur (Kumagai and Kouchi 2003; Limpens et al. 2004). Nevertheless, detailed analysis of the composite $A$. thaliana plants revealed a systemic spread of the silencing signal within the cortex and stele of chimeric roots, whereas this signal did not spread in the root epidermis. It was suggested that the reason for the absence of spread of the silencing signal could be that cells become symplastically isolated (Duckett et al. 1994).

We then studied the systemic spread of the silencing signal to the shoots of A. verticillata. In the composite plants with $\mathrm{GFP}^{+}$hairy roots resulting from the genetic transformation by the pHKN29, pHKN30, and pHKN31 vectors, all shoots exhibited a similar GUS staining pattern, suggesting that there was no significant silencing of the GUS gene linked to the presence of the 35S-GUS-hpRNA in the pHKN30- and pHKN31-cotransformed roots (Fig. $1 \mathrm{~K}$ and L). These results are different from those observed in composite plants of Arabidopsis thaliana. In the shoot, Agrobacterium rhizogenes-mediated RNAi of GFP in a $35 S-G F P$ transgenic Arabidopsis thaliana line resulted in $20 \%$ of the plants showing no or very low levels of GFP fluorescence; $20 \%$ showed no sign of silencing; and, in the remaining $60 \%$, a heterogenous pattern of fluorescence was visible, with some leaves exhibiting bright fluorescence whereas other leaves showed no GFP fluorescence at all (Limpens et al. 2004). In L. japonicus, the silencing linked to a systemic signal was limited and variable in the shoots (Kumagai and Kouchi 2003).

\section{Quantification of $G U S$ gene silencing in composite RNAi plants.}

Gene silencing was first quantified following fluorometric analysis of the GUS activity in the composite A. verticillata plants obtained from two independent $35 S$-GUS transgenic lines (referred to as A and B). Measurements were made on individual roots and shoots (Fig. 2; Table 1). In line A, genetic transformation decreased GUS activity by at least $90 \%$ in the pHKN30 (70\% of $\mathrm{GFP}^{+}$roots) and pHKN31 (100\% of $\mathrm{GFP}^{+}$ roots) vectors. The specific activities measured in line $\mathrm{B}$ were reduced in the $35 S-G U S$-RNAi roots. In all, 100 and $70 \%$ of the fluorescent $\mathrm{pHKN} 30$ and $\mathrm{pHKN} 31$ roots, respectively, showed a $90 \%$ reduction in GUS activities. These data suggest that there is no major difference regardless of which GUSRNAi construct is used, and that the 582-nt GUS-inverted repeat in pHKN30 and the 325-nt GUS-inverted repeat in pHKN31 silence the reporter gene to the same extent. These data are in agreement with those obtained in Lotus spp.. Very low or nondetectable GUS expression were observed in $35 S$ GUS roots from composite plants transformed with pHKN30 (80\% of $\mathrm{GFP}^{+}$roots) and $\mathrm{pHKN} 31\left(89 \%\right.$ of $\mathrm{GFP}^{+}$roots), indicating rather uniform silencing of the GUS gene. In $M$. truncatula, $91 \%$ of the RNAi roots were silenced and, in Arabidopsis thaliana, 86\% were silenced (Limpens et al. 2004).

GUS fluorometric activity in the aerial parts of A. verticillata plants was found to be very similar in composite plants with $\mathrm{GFP}^{+}$roots resulting from the genetic transformation with the three pHKN vectors (Table 1). These results differ from those observed in L. japonicus, where GUS activity in leaves was 25 and $33 \%$ in the pHKN30- and pHKN31-composite plants, respectively, of the GUS activity measured in pHKN29 control plants (Kumagai and Kouchi 2003).

We then used real-time qPCR to determine the level of $G U S$ transcripts in Agrobacterium rhizogenes-transformed roots that displayed fluorescent activity. The experiment was performed on roots of five independent knock-down plants of line A and showed a significant reduction in GUS mRNA. Downregulation ranged from 46 to $94 \%$ compared with the control transgenic composite plants (Fig. 3). This variation in the level of GUS transcripts is in agreement with the GUS activities observed in GUS-RNAi composite roots. Indeed, using the RNAi approach often results in different degrees of silencing of the targeted gene. Similar differences in GUS mRNA levels have been observed in silenced roots of transgenic L. japonicus (Kumagai and Kouchi 2003).

\section{Silencing of $G U S$ gene in actinorhizal nodules.}

Two months after inoculation by A. rhizogenes, $\mathrm{GFP}^{+}$composite plants obtained from different $35 S-G U S$ lines were inoculated with the strain of Frankia Allo2 in order to investigate GUS silencing in actinorhizal nodules. As previously observed (Diouf et al. 1995), the number of nodulated plants was found to be reduced in composite plants, probably due to the modification of the hormonal balance linked to the T-DNA transfer from the Ri-plasmid. Ten randomly chosen nodulated plants for each pHKN construct were histochemically analyzed. Xgluc staining revealed no or very little blue staining in 2month-old pHKN30 (data not shown) and pHKN31 (Fig. 1M) nodules. Occasionally, some blue color was seen in rare isolated cells located in the nodule cortex or in the vascular system. As previously reported (Obertello et al. 2005), some strong $35 S-G U S$ expression was seen mainly in the vascular system, around the phellogen, and in a few cortical cells of the pHKN29 nodules (Fig. 1N). Fluorometric analyses revealed nondetectable GUS activity in $\mathrm{GFP}^{+}$nodules developed on the pHKN30 and pHKN31 root systems (data not shown). Using the two vectors pHKN30 and pHKN31, Kumagai and Kouchi (2003) also have reported gene silencing in nodules of L. japonicus. The $35 S-G U S$-RNAi constructs were found to substantially reduce the reporter gene activity and accumulation of $G U S$ transcripts in two different transgenic lines of L. japonicus 
containing the GUS gene under the control of either the $35 S$ promoter or the $l j 27$ promoter from L. japonicus that is specific for nodule-infected cells.

\section{Conclusions.}

In this study, we have demonstrated that genetic transformation of A. verticillata hypocotyls with Agrobacterium rhizogenes carrying $35 S$-RNAi silencing constructs for $G U S$ lead to effective silencing of the reporter gene in transformed 35S-GUS hairy roots. Distal silencing in shoots was not observed, and the level of silencing could differ from root to root in the same plant. Silencing of GUS activity usually was greater than $90 \%$ in most transformed roots, and real-time qPCR data confirmed that the GUS gene was post-transcriptionally downregulated in roots. GUS silencing also was observed in $35 S-G U S$ actinorhizal nodules. For woody plant species such as members of Casuarinaceae with long regeneration times, this approach based on A. rhizogenes provides a rapid and efficient tool for gene function analysis in actinorhizal roots and nodules. Our data provide valuable insights into the silencing conferred by RNAi constructs under the control of the $35 \mathrm{~S}$ promoter in a tropical Casuarinaceae tree and will help to correctly interpret the observed phenotypes when silencing of plant genes involved in interactions with Frankia spp. and mycorrhiza is attempted.

\section{MATERIALS AND METHODS}

\section{Plant material and germination conditions.}

A. verticillata seed were collected in Australia and obtained from Versepuy company (Le Puy en Velay, France). After disinfection with $5 \%$ calcium hypochlorite for $30 \mathrm{~min}$, seed were germinated in sterile conditions on $\mathrm{H}$ medium (Le et al. 1986) solidified with Difco bacto-agar at $8 \mathrm{~g} \mathrm{liter}^{-1}$. The plantlets were grown for 45 days at $28^{\circ} \mathrm{C}$ with a 16 -h photoperiod and a light intensity of $50 \mu \mathrm{E} \mathrm{m} \mathrm{m}^{2-1} \mathrm{~s}^{-1}$ prior to genetic transformation by Agrobacterium tumefaciens.

\section{Binary vectors.}

The plasmid pBin-GUSint is the binary vector pBIN19 containing the GUS gene (Jefferson et al. 1987) with the IV2 intron from potato (Vancanneyt et al. 1990) and placed under the control of the $35 S$ promoter (Benfey and Chua 1990). pHKN plasmids have been described by Kumagai and Kouchi (2003). The reporter gene GFP (Niwa et al. 1999) driven by the promoter $35 \mathrm{~S}$ is present in the $\mathrm{pHKN} 29, \mathrm{pHKN} 30$, and pHKN31 vectors. The two pHKN30 and pHKN31 constructs used for silencing the GUS gene contain fragments of 582 and $325 \mathrm{nt}$, respectively, of the GUS gene (Kumagai and Kouchi 2003). Binary vectors were introduced by electroporation into the agrobacteria and the integrity of the binary plasmids was
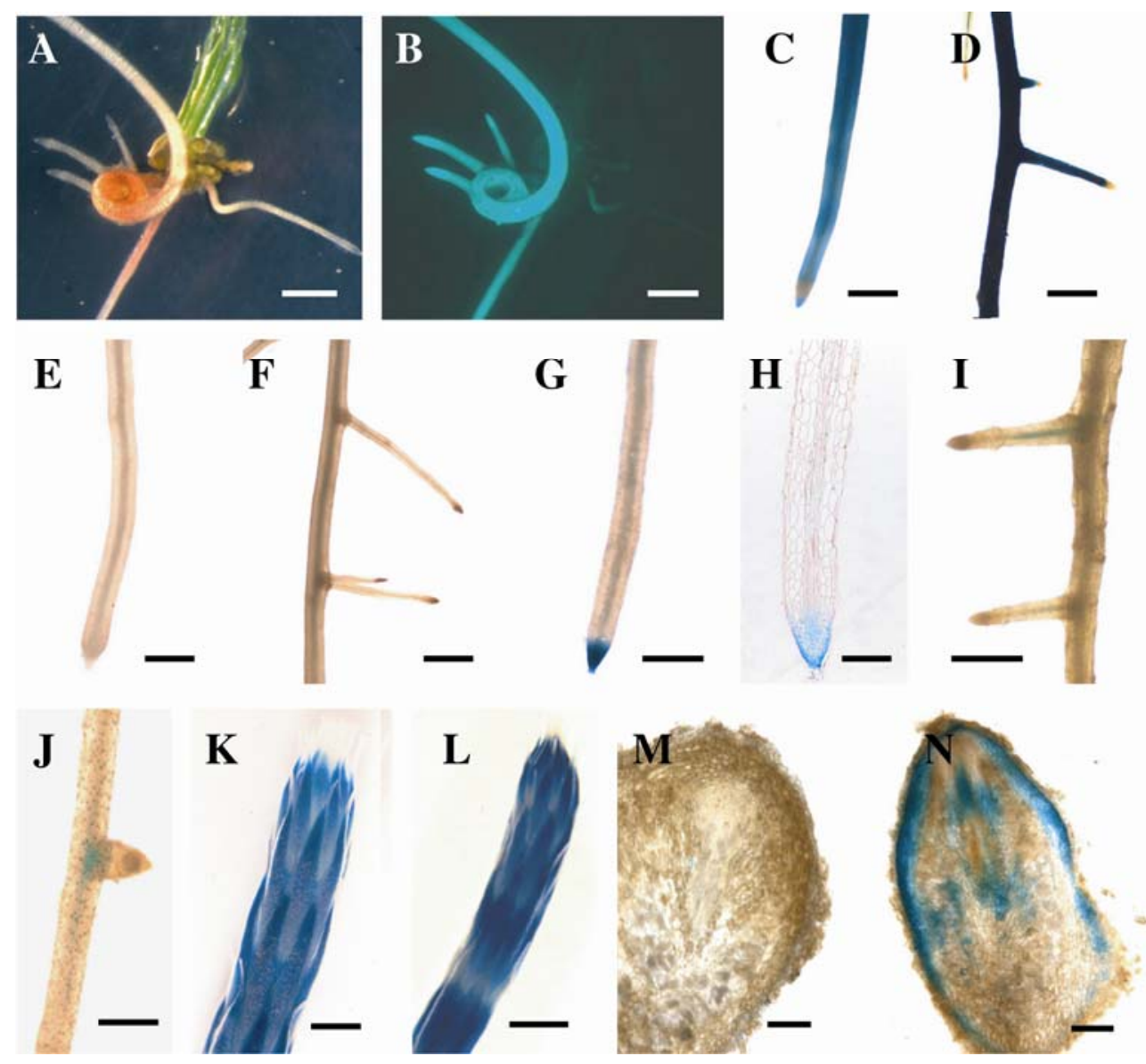

Fig. 1. $\beta$-Glucuronidase (GUS) expression in control and composite $35 S$-GUS plants of Allocasuarina verticillata silenced with $35 S$-GUS-hairpin RNA constructs. A, Hairy root developing after genetic transformation of a $35 S-G U S$ shoot of A. verticillata by A4RS(pHKN29). B, Green fluorescent protein (GFP) expression in the cotransformed roots of the composite plant shown in A. C and $\mathbf{D}, G U S$ expression in a composite hairy root system cotransformed by the control vector pHKN29; GUS was strongly expressed in $\mathbf{C}$, the main root and $\mathbf{D}$, lateral roots. $\mathbf{E}$ through $\mathbf{J}$, GUS patterns observed in $35 S$-GUS roots cotransformed with the $35 S$-GUS hairpin construct from $\mathrm{pHKN} 30$ or pHKN31; $\mathbf{E}$ and $\mathbf{F}$, some roots were completely devoid of GUS activity, whereas $\mathbf{G}$ through J, some residual GUS expression was seen in composite roots). K, GUS expression in the shoot of a composite pHKN29 control plant. L, GUS expression in the shoot of a composite pHKN30 plant with $\mathrm{GFP}^{+}$roots. $\mathbf{M}$ and $\mathbf{N}$, GUS activity observed in pseudolongitudinal vibratome sections of actinorhizal nodules excised from a composite RNA interference pHKN31 GFP ${ }^{+}$root $(\mathrm{M})$ and a control pHKN29 GFP ${ }^{+}$root $(\mathrm{N})$, respectively. Bars: A through $\mathrm{G}$ and $\mathrm{I}$ through $\mathrm{J}=5 \mathrm{~mm}, \mathrm{H}=2.5 \mathrm{~mm}, \mathrm{~K}$ and $\mathrm{L}=1 \mathrm{~mm}$, and $\mathrm{M}$ and $\mathrm{N}=100 \mu \mathrm{m}$. 
verified by Southern blot analysis performed on digested bacterial DNA (data not shown).

\section{Bacterial strains and culture media.}

The A. tumefaciens C58C1(pGV2260; pBin-GUSint) (Vancanneyt et al. 1990) and A. rhizogenes A4RS (Petit et al. 1983) were grown at $28^{\circ} \mathrm{C}$ in $\mathrm{Ag}$ medium with the appropriate antibiotics (Franche et al. 1997). A 1-day-old liquid culture of C58C1(pGV2260; pBin-GUSint) was used for the genetic transformation of $A$. verticillata. A4RS was grown on $\mathrm{Ag}$ medium solidified with Difco bacto-agar at $14 \mathrm{~g} \mathrm{liter}^{-1}$ and 4day-old colonies were used for inoculating the $35 S-G U S$ transgenic shoots. The Frankia Allo2 strain was cultivated at $26^{\circ} \mathrm{C}$ in a modified BAP medium as described by Benoist and associates (1992) and the inoculum was prepared from a 4-day-old culture in exponential growth.

Plant genetic transformation by Agrobacterium tumefaciens.

The genetic transformation of $A$. verticillata was achieved with the disarmed strain of Agrobacterium tumefaciens C58C1(pGV2260; pBinGUSint) (Franche et al. 1997). Transgenic $35 S-G U S$ calli were transferred every 3 weeks on Murashige-Skoog modified for casuarina medium (MSC; Franche et al. 1997) containing $0.5 \mu \mathrm{M}$ naphthalene acetic acid (NAA) and $2.5 \mu \mathrm{M}$ 6-benzylaminopurine, and supplemented with kanamycin at $100 \mathrm{mg} \mathrm{liter}^{-1}$ and cefotaxime at $300 \mathrm{mg} \mathrm{liter}^{-1}$. Shoots differentiated on the calli 4 months after genetic trans-
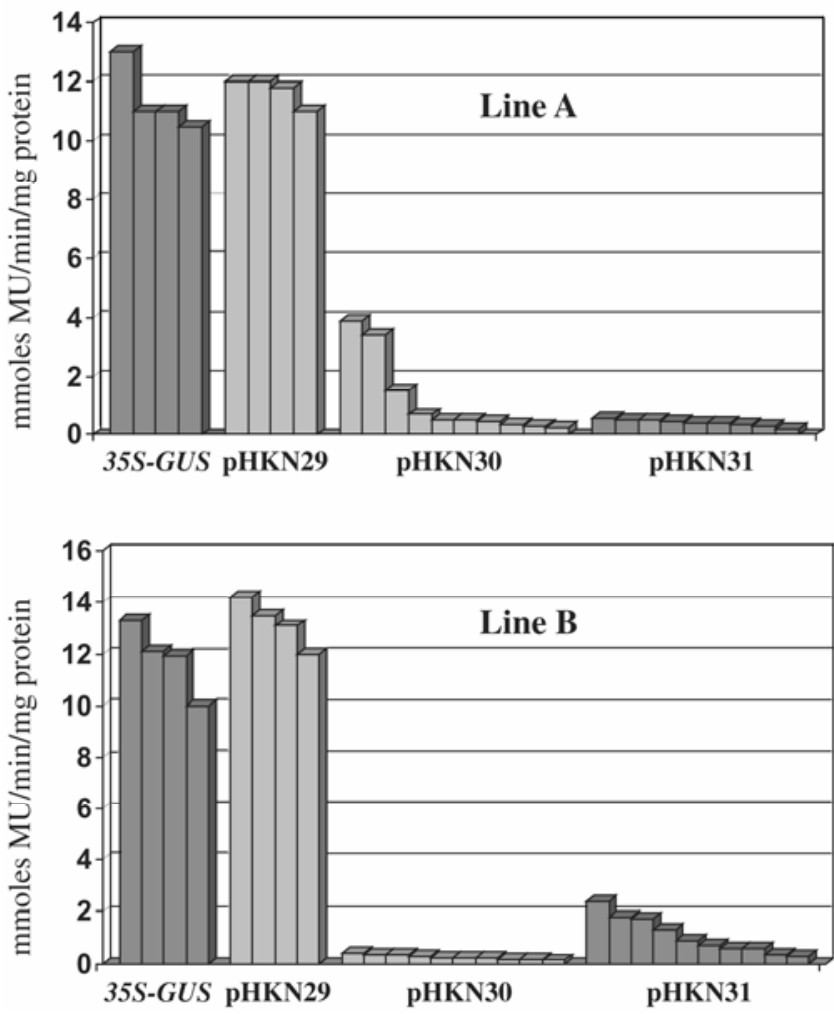

Fig. 2. Fluorometric assays of $\beta$-glucuronidase (GUS) activity in roots of control and composite green fluorescent protein $(\mathrm{GFP})^{+}$roots resulting from genetic transformation with the pHKN29, and the 35S-GUS-RNA interference pHKN30 and pHKN31 vectors. GUS silencing was studied in two transgenic 35S-GUS lines named $\mathrm{A}$ and $\mathrm{B}$. Control 35S-GUS roots were excised from transgenic plants of lines A or B obtained after genetic transformation by the Agrobacterium tumefaciens strain C58C1(pGV2260; pBIN19-GUSINT). pHKN29 is a control vector, and the $35 S-G U S$ silencing vectors pHKN30 and 31 contain a GUS hairpin fragment of 582 and 325 nucleotides, respectively, under the control of the $35 \mathrm{~S}$ promoter. $\mathrm{GFP}^{+}$ roots were collected from independent composite plants of lines A and B. formation by A. tumefaciens and were removed regularly for further inoculation by $A$. rhizogenes. Some shoots used as controls were rooted after a 3-day treatment in MSC medium containing $25 \mu \mathrm{M}$ NAA (Franche et al. 1997).

\section{A. rhizogenes transformation procedure.}

Transgenic $35 S-G U S$ shoots were excised from the calli when they reached a height of approximately $3 \mathrm{~cm}$, dipped in a fresh colony of $A$. rhizogenes A4RS containing the chosen pHKN binary vector, and grown on plates with MSC medium. After 7 days of incubation at $23^{\circ} \mathrm{C}$, transformed shoots were transferred on MSC medium containing cefotaxime at $300 \mathrm{mg}$ liter $^{-1}$ and further grown using the temperature and light conditions described for seed germination. This method produced "composite" plants with a hairy root system resulting from the T-DNA transfer from the Ri-plasmid, while the aerial part remained untransformed by A. rhizogenes (Diouf et al. 1995).

\section{Nodulation by Frankia spp.}

Composite and control plants with a root system of approximately $3 \mathrm{~cm}$ in length were placed in tubes containing quarterstrength sterile Hoagland liquid medium with ammonium sulfate, $\mathrm{pH}$ 5.6, at $17 \mathrm{mg} \mathrm{liter}^{-1}$ (Santi et al. 2003). After 1 month,

Table 1. $\beta$-Glucuronidase (GUS) activity in shoot and root extracts from control 35S-GUS and composite $35 S-G U S$ RNA interference plants of Allocasuarina verticillata lines $\mathrm{A}_{\text {and }} \mathrm{B}^{\mathrm{a}}$

\begin{tabular}{lcc}
\hline & \multicolumn{2}{c}{ GUS activity (mmoles MU/min/mg protein) } \\
\cline { 2 - 3 } Extracts & Line A & Line B \\
\hline Shoots & & \\
35S-GUS & $13.7 \pm 1.6$ & $14.2 \pm 1.1$ \\
pHKN29 & $13.5 \pm 1.8$ & $13.9 \pm 1.1$ \\
pHKN30 & $12.7 \pm 1.8$ & $13.4 \pm 1.2$ \\
pHKN31 & $14.7 \pm 1.6$ & $14.2 \pm 1.1$ \\
Roots & & \\
35S-GUS & $11.4 \pm 1.1$ & $11.8 \pm 1.4$ \\
pHKN29 & $11.7 \pm 0.5$ & $13.3 \pm 0.9$ \\
pHKN30 & $1.2 \pm 1.3$ & $0.25 \pm 0.1$ \\
pHKN31 & $0.4 \pm 0.1$ & $1 \pm 0.7$ \\
\hline
\end{tabular}

a Transgenic 35S-GUS plants result from the genetic transformation of $A$. verticillata by the disarmed strain of Agrobacterium tumefaciens C58C1(pGV2260; pBIN-GUSint). Composite pHKN plants possess a hairy root system resulting from the genetic transformation of $35 S$-GUS shoots by $A$. rhizogenes A4RS containing one of the pHKN vectors. Values are the mean \pm standard errors.

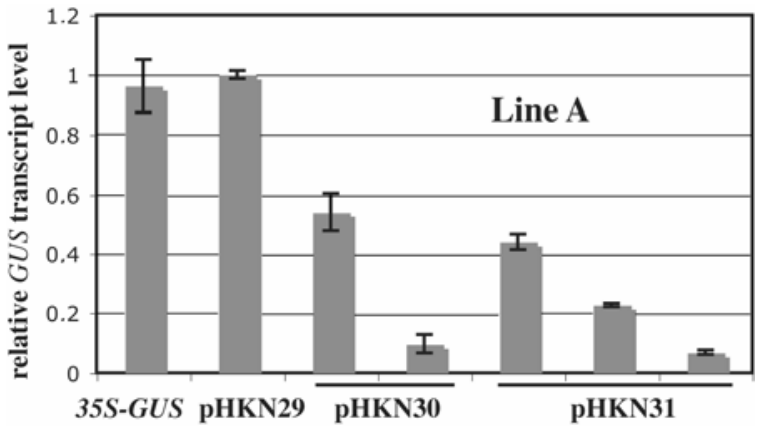

Fig. 3. Quantification of $\beta$-glucuronidase (GUS) transcripts in roots of Allocasuarina verticillata transgenic line A using real-time quantitative polymerase chain reaction. Total RNAs were isolated from roots of five independent 35S-GUS-RNA interference (RNAi) plants and reverse transcribed. The ubiquitin gene was used as reference. Expression levels are given relative to transgenic control plant transformed with pHKN29. Error bars indicate standard errors of the mean of three technical replicates. A29: transgenic control. A30: 35S-GUS-RNAi plants transformed with pHKN30. A31: 35S-GUS-RNAi plants transformed with pHKN31. 
the nutrient solution was discarded and each plant was inoculated with $2 \mathrm{ml}$ of a suspension of Frankia Allo2 at a density corresponding to $25 \mu \mathrm{g} \mathrm{ml}^{-1}$ of protein. After $2 \mathrm{~h}$ of contact between the plant root system and the actinomycete, the tubes were filled up with nitrogen-free Hoagland solution at $\mathrm{pH} 6.8$. Roots were protected from the light and nodule initiation was monitored weekly.

\section{Histochemical GUS staining.}

For histochemical staining, shoots and roots were immersed overnight at $37^{\circ} \mathrm{C}$ in a $50 \mathrm{mM}$ sodium phosphate buffer $(\mathrm{pH}$ 7.0) containing $1 \mathrm{mM} \mathrm{X}$-gluc, $0.5 \mathrm{mM} \mathrm{K}_{3} \mathrm{Fe}(\mathrm{CN})_{6}$ and $\mathrm{K}_{4} \mathrm{Fe}(\mathrm{CN})_{6}$, and $1 \%$ (vol/vol) Triton $\mathrm{X}-100$, as recommended by Jefferson and associates (1987). The stained plant material then was fixed for $1 \mathrm{~h}$ in a solution containing $5 \%$ formaldehyde, $5 \%$ acetic acid, and $50 \%$ ethanol, washed several times in $70 \%$ (vol/vol) ethanol, and photographed under a stereomicroscope.

Because the substrate X-gluc does not readily penetrate whole actinorhizal nodules, symbiotic roots first were embedded in $3 \%$ agarose and sliced into $40-$ to $50-\mu$ m-thick sections using a vibratome (Leica VT1000E) prior to histochemical treatment. Sections then were stained and fixed as described above, dehydrated, and mounted on glass slides with $50 \%$ glycerin (vol/vol). They were examined under a light microscope and photographed using a digital camera.

\section{Fluorometric GUS quantification.}

Quantitative assays of GUS activity were performed in extracts of aerial parts, roots, and nodules of transgenic plants using 4-methylumbelliferone $\beta$-D-glucuronide (MUG) as substrate (Jefferson et al. 1987). Plant material was ground in 250 $\mu \mathrm{l}$ of extraction buffer (50 mM sodium phosphate, $\mathrm{pH} 7.0 ; 1$ mM EDTA; $0.1 \%$ [wt/vol] sarcosyl; and $0.1 \%$ Triton $\mathrm{X}-100$ ). Protein concentrations were estimated according to the method of Bradford (1976) using a range of bovine serum albumin as standard. GUS activity then was quantified with a Fluoroskan II Fluorescent Microplate Reader (Labsystems) with excitation at $355 \mathrm{~nm}$ and emission at $460 \mathrm{~nm}$. The accumulation of 4methyl umbelliferone (4-MU) was expressed as $\mu$ mol of MU $\mathrm{min}^{-1} \mathrm{mg}^{-1}$ of extracted proteins.

\section{GFP expression using epifluorescence microscopy.}

Epifluorescence microscopy was carried out using a Leica MZ FLIII stereomicroscope with a fluorescent light source and equipped with filters giving an excitation spectrum between 475 and $495 \mathrm{~nm}$ and a barrier filter between 520 and $550 \mathrm{~nm}$. Photographic images were captured using a Leica automatic camera.

\section{Real-Time qPCR.}

Total RNAs were extracted from transgenic composite roots using the RNeasy plant mini kit (Qiagen GMBH, Hilden, Germany) as recommended by the manufacturer. RNAs from each sample were quantified with Quant-iT Ribogreen RNA reagent (Molecular Probes, Invitrogen, Eugene, OR, U.S.A.). Total RNAs (200 ng) were reverse transcribed using SuperScriptIII $\mathrm{H}^{-}$reverse transcriptase (Invitrogen, San Diego, CA, U.S.A.) and oligo-dT $\mathrm{T}_{12-18}$. Real-time qPCR then was carried out using the FullVelocity SYBR green QPCR master mix (Stratagene, La Jolla, CA, U.S.A.) in a total volume of $25 \mu \mathrm{l}$ with the couple of primers specific to the GUS gene (GUS-F 5'-TTAACTA TGCCGGAATCCATCGC and GUS-R 5'-AACGCTGACATC ACCATTGGC-3') (Yang et al. 2005). Ubiquitin gene ( $\mathrm{Cg} U b i)$ expression was chosen as a reference (Hocher et al. 2006). The FullVelocity cycling PCR program on an MX 3005P (Stratagene) was as follows: 1 cycle at $95^{\circ} \mathrm{C}$ for $5 \mathrm{~min}$; 40 cy- cles at $95^{\circ} \mathrm{C}$ for $10 \mathrm{~s}$ and $60^{\circ} \mathrm{C}$ for $30 \mathrm{~s}$; ended by 1 cycle at $95^{\circ} \mathrm{C}$ for $1 \mathrm{~min}, 60^{\circ} \mathrm{C}$ for $30 \mathrm{~s}$, and $95^{\circ} \mathrm{C}$ for $30 \mathrm{~s}$. Reactions were run in three replicates and the comparative thresholdcycle method was performed to quantify GUS expression. Abundance of GUS transcripts was normalized to ubiquitin and corrected according to the results of the PCR as described by Hocher and associates (2006).

\section{ACKNOWLEDGMENTS}

We thank H. Kouchi (National Institute of Agrobiological Sciences, Ibaraki, Japan) for providing the $\mathrm{pHKN}$ vectors, O. Voinnet (Institut de Biologie Moléculaire des Plantes, Strasbourg, France) for helpful discussion concerning gene silencing, and M. Collin (Institut de Recherche pour le Development [IRD], Montpellier, France) for technical assistance in cytology. This work was supported by the IRD and by the Agence Nationale de la Recherche (ANR) Blanc project NewNod (ANR-06-BLAN-0095). M. Nambiar-Veetil was financially supported by a grant from the Department of Biotechnology, Ministry of Science and Technology, Government of India. C. Zhong was supported by a Département Soutien et Formation fellowship from IRD.

\section{LITERATURE CITED}

Baulcombe, D. 2004. RNA silencing in plants. Nature 431:356-363.

Benfey, P. N., and Chua, N. H. 1990. The cauliflower mosaic virus $35 \mathrm{~S}$ promoter: Combinational regulation of transcription in plants. Science 250:959-966.

Benoist, P., Müller, A., Diem, H. D., and Schwencke, J. 1992. High-molecular-mass multicatalytic proteinases complexes produced by the nitrogenfixing actinomycete Frankia strain BR. J. Bacteriol. 174:1495-1504.

Benson, D. R., and Silvester, W. B. 1993. Biology of Frankia strains, actinomycete symbionts of actinorhizal plants. Microbiol. Rev. 57:297-319.

Boisson-Dernier, A., Chabaud, M., Garcia, F., Bécard, G., Rosenberg, C., and Barker, D. G. 2001. Agrobacterium rhizogenes-transformed roots of Medicago truncatula for the study of nitrogen-fixing and endomycorrhizal symbiotic associations. Mol. Plant-Microbe Interact. 18:12691276.

Bradford, M. M. 1976. A rapid and sensitive method for the quantification of microgram quantities of protein utilizing the principle of protein-dye binding. Anal. Biochem. 72:248-254.

Dénarié, J., Debellé, F., and Promé, J. C. 1996. Rhizobium lipochitoligosaccharides nodulation factors: Signaling molecules mediating recognition and morphogenesis. Annu. Rev. Biochem. 65:503-535.

Diouf, D., Gherbi, H., Prin, Y., Franche, C., Duhoux, E., and Bogusz, D. 1995. Hairy root nodulation of Casuarina glauca: A system for the study of symbiotic gene expression in an actinorhizal tree. Mol. PlantMicrobe Interact. 8:532-537.

Duckett, C. M., Oparka, K. J., Prior, D. A. M., Dolan, L., and Roberts, K. 1994. Dye-coupling in the root epidermis of Arabidopsis is progressively reduced during development. Development 120:3247-3255.

Franche, C., Diouf, D., Le, Q. V., N'Diaye, A., Gherbi, H., Bogusz, D., Gobé, C., and Duhoux, E. 1997. Genetic transformation of the actinorhizal tree Allocasuarina verticillata by Agrobacterium tumefaciens. Plant J. 11:897-904.

Hamilton, A. J., Brown, S., Yuanhai, H., Ishizuka, M., Lowe, A., Solis, A. G. A., and Grierson, D. 1998. A transgene with repeat DNA causes high frequency, post-transcriptional suppression of ACC-oxidase gene expression in tomato. Plant J. 15:737-746.

Hannon, G. J. 2002. RNA interference. Nature 418:244-251.

Hocher, V., Auguy, F., Argout, X., Laplaze, L., Franche, C., and Bogusz, D. 2006. Expressed sequence-tag analysis in Casuarina glauca actinorhizal nodule and root. New Phytol. 169:681-688.

Jefferson, R. A., Kavanagh, T. A., and Bevan, M. W. 1987. GUS fusion: $\beta$ glucuronidase as a sensitive and versatile gene fusion marker in higher plants. EMBO (Eur. Mol. Biol. Organ.) J. 6:3901-3907.

Kobayashi, K., and Zambryski, P. 2007. RNA silencing and its cell-to-cell spread during Arabidopsis embryogenesis. Plant J. 50:597-604.

Kumagai, H., and Kouchi, H. 2003. Gene silencing by expression of hairpin RNA in Lotus japonicus roots and root nodules. Mol. Plant-Microbe Interact. 16:663-668.

Kumagai, H., Kinoshita, E., Ridge, R. W., and Kouchi, H. 2006. RNAi knock-down of ENOD40s leads to significant suppression of nodule formation in Lotus japonicus. Plant Cell Physiol. 47:1102-1111.

Le, Q. V., Bogusz, D., Gherbi, H., Lappartient, A., Duhoux, E., and Franche, C. 1996. Agrobacterium tumefaciens gene transfer to Casuarina glauca, a tropical nitrogen-fixing tree. Plant Sci. 118:57-69. 
Limpens, E., Franken, C., Smit, P., Willemse, J., Bisseling, T., and René Geurts, R. 2003. LysM domain receptor kinases regulating rhizobial Nod factor-induced infection. Science 302:630-633.

Limpens, E., Ramos, J., Franken, C., Raz, V., Compaan, B., Franssen, H., Bisseling, T., and Geurts, R. 2004. RNA interference in Agrobacterium rhizogenes-transformed roots of Arabidopsis and Medicago truncatula. J. Exp. Bot. 55:983-992.

Meyer, S., Nowak, K., Sharma, V. K., Schulze, J., Mendel, R. R., and Hänsch, R. 2004. Vectors for RNAi technology in poplar. Plant Biol. 6:100-104.

Niwa, Y., Hirano, T., Yoshimoto, K., Shimizu, M., and Kobayashi, H. 1999. Non-invasive quantitative detection and applications of non-toxic, S65T-type green fluorescent protein in living plants. Plant J. 18:455463.

Normand, P., Lapierre, P., Tisa, L. S., Gogarten, J. P., Alloisio, N., Bagnarol, E., Bassi, C. A., Berry, A. M., Bickahart, D. M., Daubin, V., Demange, N., Francino, M. P., Goltsman, E., Marechal, J., Martinez, M., Mastronunzio, J. E., Mullin, B. C., Niemann, J., Pujic, P. Rawnsley, T., Rouy, Z., Schenowitz, C., Sellstedt, A., Tavares, F., Tomkins, J., Vallenet, D., Valverde, C., Wall, L. G., Wang, Y., Medigue, C., and Benson, D. R. 2007. Genome characteristics of facultatively symbiotic Frankia sp. strains reflect host range and host plant biogeography. Genome Res. 17:7-15.

Obertello, M., Santi, C., Sy, M. O., Laplaze, L., Auguy, F., Bogusz, D., and Franche, C. 2005. Comparison of four constitutive promoters for the expression of transgenes in the tropical nitrogen-fixing tree Allocasuarina verticillata. Plant Cell Rep. 24:540-548.

Obertello, M., Santi, C., Svistoonoff, S., Hocher, V., Auguy, F., Laplaze, L., Bogusz, D., and Franche, C. 2007. Casuarina glauca. Pages 433445 in: Biotechnology in Agriculture and Forestry, Vol. 60, Transgenic Crop V. E. C. Pua and M. R. Davey, eds. Springer Verlag, Berlin, Heidelberg.

Pawlowski K. 2002. Actinorhizal symbioses. Pages 167-189 in: Nitrogen Fixation at the Millennium. G. J. Leigh, ed. Elsevier Science, New York.

Pawlowski, K., and Bisseling, T. 1996. Rhizobial and actinorhizal symbioses: What are the shared features? Plant Cell 6:1899-1913.
Petit, A., David, C., Dahl, G. A., Ellis, J., Guyon, P., Casse-Delbart, F., and Tempé, J. 1983. Further extension of the opine concept: Plasmids in Agrobacterium rhizogenes cooperate for opine degradation. Mol. Gen. Genet. 190:204-214.

Santi, C., Svistoonoff, S., Constans, L., Auguy, F., Duhoux, E., Bogusz, D., and Franche, C. 2003. Choosing a reporter for gene expression studies in transgenic actinorhizal plants of the Casuarinaceae family. Plant Soil 254:229-237.

Small, I. 2007. RNAi for revealing and engineering plant gene functions. Curr. Opin. Biotechnol. 18:148-153.

Smith, N. A., Singh, S. P., Wang, M. B., Stoujesdijk, P. A., Green, A. G., and Waterhouse, P. M. 2000. Total silencing by intron-spliced hairpin RNAs. Nature 407:319-320.

Vancanneyt, G., Schmidt, R., O'Connor-Sanchez, A., Willmitzer, L., and Rocha-Sosa, M. 1990. Construction of an intron-containing marker gene: Splicing of the intron in transgenic plants and its use in monitoring early events in Agrobacterium-mediated plant transformation. Mol. Gen. Genet. 220:245-250.

Vessey, J. K., Pawlowski, K., and Bergman, B. 2005. Root-based $\mathrm{N}_{2}$-fixing symbioses: Legumes, actinorhizal plants, Parasponia sp. and cycads. Plant Soil 274:51-78.

Voinnet, O., and Baulcombe, D. C. 1997. Systemic signalling in gene silencing. Nature 389:553.

Voinnet, O., Vain, P., Angell, S., and Baulcombe, C. 1998. Systemic spread of sequence-specific transgene RNA degradation in plants is initiated by localized introduction of ectopic promoterless DNA. Cell 95:177-187.

Waterhouse, P. M., and Helliwell, C. A. 2003. Exploring plant genomes by RNA-induced gene silencing. Nat. Rev. Genet. 4:29-38.

Waterhouse, P. M., Graham, M. W., and Wang, M. B. 1998. Virus resistance and gene silencing in plants can be induced by simultaneous expression of sense and antisense RNA. Proc. Natl. Acad. Sci. U.S.A. 95:13959-13964.

Yang, L., Ding, J., Zhang, C., Jia, J., Weng, H., Liu, W., and Zhang, D. 2005. Estimating the copy number of transgenes in transformed rice by real-time quantitative PCR. Plant Cell Rep. 23:759-63. 